\title{
Innovation of Engineering Professional Talent Cultivation Mode on School-Enterprise Cooperation Based on Modern Urban Agriculture
}

\author{
Yu Shi \\ College of Engineering and Technology \\ Tianjin Agricultural University \\ Tianjin, China \\ syych83@tjau.edu.cn \\ Chuanlin $\mathrm{Li}^{*}$ (Corresponding Author) \\ College of Engineering and Technology \\ Tianjin Agricultural University \\ Tianjin, China \\ 361473215@qq.com
}

\author{
Liyun Bian \\ Academic Affairs Office \\ Tianjin Agricultural University \\ Tianjin, China \\ 519263203@qq.com \\ Hua Liu \\ College of Engineering and Technology \\ Tianjin Agricultural University \\ Tianjin, China \\ 41599386@qq.com
}

\begin{abstract}
The talent cultivation of school enterprise cooperation is an effective way to cultivate high quality and high skilled talents. It is also an important carrier of the cooperative education of industry university research, and is the important content of improving the level of talent training work. Further strengthen the cooperation of schools enterprises, promote the combination between manufacture and learning. Through the construction and design of the talent training mode of the school enterprise cooperation in the agricultural colleges and universities, cultivate high-quality skilled talents, solve the outstanding problems of the teaching process in engineering major of agricultural universities, enhance students' professional ability, method ability and social ability, improve the comprehensive quality of students. Actively explore the advantages and disadvantages of school enterprise cooperation talent cultivation mode, as well as solve the matching problem between the number and quality of skilled talents and social demands. It has a long and profound practical significance to the development of agricultural economy in Tianjin area.
\end{abstract}

Keywords—school-enterprise; cooperation; requirement; cultivation mode

\section{INTRODUCTION}

School-enterprise cooperation is an effective means to seek their own development space and serve modern urban agriculture for the engineering professional in agricultural universities, which is the process of the university and the employer to participate in the talent cultivation. It can achieve "win-win" situation between the universities and enterprises, which could promote mutual penetration between the concept of higher education and enterprise management, in order to cultivate talents with high skill and practical ability meet the social requirement. Due to the restriction of the development of some agricultural universities, there are several problems on

\footnotetext{
1. Educational Science Program of Tianjin (HE3077);

2. Guidance- Development Program on Educational Reform and Innovation for Teachers of Tianjin Agricultural University (20170702).
}

the school-enterprise cooperation, such as the low level of cooperation, the lack of depth and breadth, the two sides do not specify the specific dimensions of power and responsibility arrangements. As a result, the teaching mode still focuses on the academic orientation, the orientation of talent cultivation target is inaccurate, and the teaching content cannot keep up with the development of agricultural industry. As a kind of effective education form to cultivate universities' comprehensive ability and improve universities' employment competitive ability, we should explore and innovate in practice, learn from the experience of foreign agricultural universities to find a new mode which is suitable for the characteristics of engineering professional in agricultural universities in our country.

\section{The Gap Between the Practical Skills of ENGINEERING UNDERGRADUATES IN AGRICULTURAL UNIVERSITIES AND THE EXPECTED SKILLS OF EMPLOYERS}

Universities and enterprises are supplier and demander of the labor market, the mismatch between the talent and the market demand will cause the imbalance in supply and demand of labor quality [1]. This paper has chosen more than 20 employers in Tianjin and Beijing area and graduates major in Agricultural Mechanization, Automation and Measurement and Control Technology and Instrumentation, New energy science and Engineering and Electrical Engineering and Automation who have graduated or in the internship within three years as the research objects. Enterprises require employees to have a sense of responsibility, the courage to self criticism, good cooperation, and stand up to setbacks, attention to learning, practice and Practice. This is the employer's advice to the new staff, but also the social requirements to the professional quality of undergraduates. 
With the increase of the content of science and technology, the demand for high skilled talents is increasing. The enterprises urgently need a large number of applied talents with knowledge and ability. Enterprise employment standards transform to the ability to work as the standard, application ability and innovation ability are more important. The enterprise need high quality technical applied talents with ability to organize, implement, analyze and solve technical problems.

The ability requirements of the engineering graduates which employers need mainly focused on practical ability, professional competence, and innovation ability and communication skill. The ability of undergraduate needed more urgently shows that there are differences between practical skills of graduates and market demand[2]. Mainly reflected in difficult employment, it is difficult to find a satisfactory job, while most of the employers could not find the graduates with strong practical ability and high comprehensive quality. In other words, the graduates cannot find a suitable job while the enterprises cannot find a suitable talent"[1]. Society needs talents, while universities are the cradle of talents for the society. Practice can transform a person. As a place of practice, enterprise will be sufficient to test a person's ability and knowledge level. Only deficiencies continue to be exposed, there will be progress, only be good at sum up using theory after practice, there will be a leap to improve, which could create a group of man of tremendous promise needed by society with real ability and management ability.

The template is used to format your paper and style the text. All margins, column widths, line spaces, and text fonts are prescribed; please do not alter them. You may note peculiarities. For example, the head margin in this template measures proportionately more than is customary. This measurement and others are deliberate, using specifications that anticipate your paper as one part of the entire proceedings, and not as an independent document. Please do not revise any of the current designations.

\section{Problems Existing in Talent Cultivation Mode OF SCHOOL ENTERPRISE COOPERATION}

To cultivate talents who meet the demand of the market, it is often difficult to achieve only rely on the resources and environment of school, which must have the strong support of modern enterprises, accept the influence of corporate culture, temper in the corporate environment. So, school-enterprise cooperation is an effective way to cultivate the practical engineering talents closed to the production practice. More and more attention has been paid to such cooperation, which initially form a unique education and employment mode. It plays a positive role in cultivating practical and technical talents[3]. But at the level of training, there is still a gap between the demands of enterprises.

\section{A. Content and Level of Cooperation}

Whether the undergraduates have achieved the established objectives, the enterprises have an important right to speak on this issue. The undergraduates cultivated by no matter what kind of educational mode should meet the job requirements of professional skills and professional ethics after entering the enterprise[4]. Due to the current school-enterprise cooperation mostly stay in the shallow level of cooperation solving experimental and practical training base and so on. It can only exist cooperation relationship in a certain field or related areas. Enterprise has no direct cooperation with the school in the cooperative education, professional development, curriculum development, teacher building, etc. The content of cooperation is lack of systematical analysis, cultivation programs for undergraduates, professional planning and curriculum adjustment, which is always a temporary cooperation on individual fields and projects. No long-term stable operation mechanism was established.

\section{B. Existing Gap Between the Cultivation Target of Talents and the Requirement of Enterprises}

The content and level of the school-enterprise cooperation are not deep enough. The following problems are hidden in the cultivation target of talent:

- Although the undergraduates cultivated by such cooperation are strong have strong practical ability, the theoretical foundation is weak, reflecting the lack of flexibility in the practice operation process.

- The students lack understanding and awareness of enterprise culture. Teaching of the universities on service consciousness, such as professional ethics, professional standards, professional ethics and so on, are not deeply, which leads to the phenomenon of students' Job Burnout.

- Education and business demand are derailed. The undergraduates lack the sense of teamwork, communication and innovation. There is no direct investigation and evaluation method in the school. These are also the ignored parts of the existing cultivation mode.

\section{Passive Cooperation Mode}

For the university or the enterprise, the training content is usually the basic operation on the basic equipment. For the equipments which are expensive and used in production practice, they only organized visits, or few students could use. School-enterprise cooperation is often based on one party initiative. School takes the initiative to cooperate with the enterprise mainly in order to establish a teaching experimental base or improve the employment rate of graduates. Due to the restrictions of subject setting and educational system, the school cannot provide more available resources to the enterprise. The utilization of the training base is low.

\section{The Ability of Teachers and Enterprise Mentors Needs to be Improved}

Teachers lack practical teaching experience with professional level, and enterprise mentors lack systematic theoretical knowledge, which led to a certain degree of discount on the teaching ability of the teachers and enterprise mentors. In addition, students put forward negative view on 
the existing teaching attitude and teaching methods of teachers In terms of teaching methods, some teachers still use traditional inculcation, especially for the content is difficult and the data derived from the complex curriculum. It is difficult for the teachers to grasp the interest of the student, who have limited basic teaching skills. Sometimes it is difficult to master the classroom.

\section{INNOVATION OF ENGINEERING PROFESSIONAL TALENT Cultivation MODE ON SCHOOL-ENTERPRISE COOPERATION BASED ON MODERN URBAN AGRICULTURE}

In order to service regional economic development better and transport high-quality high-tech talents for enterprises, the engineering professional in agricultural universities should formulate a new talents cultivation mode on school-enterprise cooperation meeting technical and development requirements of the region on the basis of the long-term stable cooperation relations established between the enterprises. It should achieve cultural integration, cost sharing, clear objectives, sharing of resources, mutual benefit and win-win situation.

\section{A. The Cultivation Target is to Cultivate the Professional Competence for the Students as a Core and Pay Attention to Cultural Integration}

The cultivation target is related to the direction and specification of talents cultivation, such formulation on the cooperation of school-enterprise should follow the guidance of cultivation target. To cultivate professional competence of students should be the core of the cultivation mode on schoolenterprise cooperation. Employees need deep professional theory and technology, good method skills, strong learning ability and adaptability to the external environment. Cultural integration take advantage of respective advantages of the schools and enterprises on the talents cultivation, which can combine practical skills obtained in enterprise and the theoretical knowledge in school. School education environment where teach knowledge as the main and the production site environment where could obtain practical experience directly should be integrated. The teaching mode in school and business management, business mode should be integrated. Spread enterprise culture into school, so that, the undergraduates could be able to accept the influence of enterprise in the stage of learning and familiarize with the professional norms and requirements in the future.

\section{B. Professional Construction Focus on the Coordination Between Market Mechanisms and Demand for Talents in Enterprise}

Professional construction is a systematic project for both the school and the enterprise. It not only maintains the quality of school life and the creation of school brand and reputation, but also the undergraduates could obtain employment smoothly relying on enterprises more importantly. The role of the enterprises played in the construction of professional connotation is far stronger than the school. The enterprises could provide more operational and multi direction adjustment according to the original problems with strong rigid and narrow surface of the school, in order to meet the seamless links between the professional construction and needs of the enterprises.

\section{Curriculum Oriented by the Professional Competence with Clear Purpose}

In the teaching program, the first two years are the school cultivating stage, which could mainly cultivate the basic theoretical knowledge and solid professional foundation of the undergraduates. The next two years are the stage of joint training program of school-enterprise, which could mainly learn professional knowledge and train technology application competence in real or simulation technology jobs. Adapt to the job changes, dynamically develop curriculum. The curriculum should agree with the post requirements and coordinate with the development of the enterprises. Such cooperation complement relevant new knowledge, new technology, new process and new method in time, which integrates the corporate philosophy, corporate culture, business management into the teaching content. It makes the course more targeted, practical and forward-looking with corporate personality and professional characteristics.

\section{Training Base Construction Should Pay Attention to the Joint Construction of School and Enterprise, Cost Sharing, Resource Sharing}

Cost sharing means the school and enterprise both sides use their advantages and invest in human, material and financial resources. The school and enterprise realize the cultivation of talents on the base of undertaking the responsibility of personnel training, providing cost funds, bearing the risk of education, sharing the benefits of running schools together[5]. Construct the training base of the cultivation mode on school-enterprise cooperation should realize three abutments. Firstly, the equipment needed in practice should equivalent to the technology platform in enterprise. Secondly, the technical level of professional teachers should equivalent to the technical level of engineer in enterprise. Thirdly, the cultivation target should equivalent to the professional skills needed by the enterprise. The enterprises invest in advanced equipments and funds in order to provide a training base in the university. They also could construct training base outside the university, which realize the resource sharing on teachers, teaching facilities, production equipments and make up for each other's deficiencies.

\section{E. The Construction of Teachers Team}

The construction of teachers' team is one of the most important links in the process of Constructing Talents Training mode. Enterprises have the advantages of human resources; can supply highly skilled engineering and technical personnel, management personnel, senior technicians as a part-time teacher team to the school. During the process of teaching practical experience, they could convey to students the regional economic development trends, changes in industrial structure, changes in industry positions and other information. Besides the classroom teaching, the enterprise can regularly send experts to the occupation school to do academic reports and lectures. At the same time teachers can 
also visit and learn at the enterprise, it is also a good opportunity for teachers to learn and practice. This is undoubtedly a win-win opportunity for school teachers, students and employees. Similarly, colleges and universities should establish appropriate learning and learning system. One is the teachers to learn the advanced experience of enterprise so to enhance self occupation ability and practice ability, on the other hand is the enterprise engineering personnel to return to college to get advanced degree, make up for the blind spot of theoretical knowledge, to guide the practice better.

\section{F. The Construction of College and University Teachers}

Establishing a quality evaluation which taking the professional ability as the evaluation standard.

Professional standards are the indicators of students' ability to work, before joining the work; students must pass the appropriate vocational qualification test. The quality evaluation system of school enterprise cooperation on the basis of enterprise standards and professional standards should pay attention to the following aspects: (1) The enterprise provides the enterprise standard and the occupation standard pattern for the school, provides the requirements about the knowledge, the skill and the professional quality when the students is graduating, provides the job requirements and so on. (2) Improve the examination and assessment system, subvert the traditional examination mode, and pay attention to the evaluation about process, focusing on the students' ability to operate and professional knowledge. (3) Establish experts group for monitoring and evaluation of the teaching quality, establish multivariate evaluation subject, supervise and control the quality of theory teaching and practice teaching at any time, and give full play to the group of experts on the sensitivity and adaptability of training objectives, timely education supervision. (4) The interaction between enterprises and schools must have a clear goal, in the process of running to track management, and provide the basis for the true meaning of the interaction between school and enterprise.

\section{CONCLUSIONS}

Establishing talent cultivation mode on school-enterprise cooperation based on modern urban agriculture, which is beneficial to strengthen the practical ability training of students, strengthen the accumulation of practical experience of teachers, and strengthen the joint research of universities and enterprises, could constantly improve the ability of innovation and entrepreneurship of the students in the related fields, and to serve the economic and social development. In order to effectively cultivate high-quality and high skilled talents, in practice we need to constantly sum up experience, to avoid the limitations of talent cultivation and sustainable development, to create a good atmosphere of cooperation, deepen cooperation content, establish a long-term effective mechanism of cooperation, to meet the social needs of highquality and high skilled talents.

\section{ACKNOWLEDGMENT}

This work was financially supported by the Educational Science Program of Tianjin (HE3077) and GuidanceDevelopment Program on Educational Reform and Innovation for Teachers of Tianjin Agricultural University (20170702).

\section{REFERENCES}

[1] Yanhui Lu, Employment ability oriented to construct the meaning of practical teaching system in colleges and universities and the way[J]. Work and Abroad, 14, 2011, pp. 13-14

[2] Gulimire Agemaiti,Yu Shi,Yan Wang,Huiru Jin,The research on the construction of undergraduate teaching quality in employabilityoriented[C],2015 International Conference on Social Science, Education Management and Sports Education,2015, pp:1393-1396.

[3] Zhu Yutao, The comparison and suggestions of Chinese and foreign agricultural universities university-enterprise cooperation personnel training mode[J], World Agriculture, 2014(1).

[4] Li Yunfei, Research on the Personnel Training Mode of SchoolEnterprise Cooperation in the Major of Machinery Manufacturing Technology[D], Shenyang Normal University, 2013.

[5] $\mathrm{Hu}$ Tianming, Exploration and Practice of University Enterprise Cooperation Mode in Cultivating Applied Undergraduate Talents[J], Heilongiiang Science and Technology Information, 2008(13):154-155. 